\title{
Selection of schemes for delivery of foreign trade cargoes using digital technologies
}

\author{
Olga Efimova $^{1 *}$, Sergey Vakulenko ${ }^{1}$, Petr Kurenkov ${ }^{1}$, Naida Magomedova ${ }^{1}$, and Elena \\ Rudakova $^{1}$ \\ ${ }^{1}$ Russian University of Transport (RUT), 127994 Moscow, Russia
}

\begin{abstract}
The article deals with the problem of transport management in all types of communication in the context of digitalization. Possible schemes of interaction between the subjects of the transport services market and various modes of transport in foreign trade transportations in mixed messages are presented. It is recommended that when choosing a route for transport and freight flows, take into account all types of interaction and coordination of activities of various types of transport, as well as subjects of transport and other markets.
\end{abstract}

\section{Introduction}

Freight traffic management is the basis for efficient and high-quality transport services for the country's economy and individual economic subjects of the market.. It is known that the commercial success of a product or transport service depends not only on the ratio of price and quality, investment in advertising, but also on how well chosen schemes of delivery, payment, transportation and storage. The advantages of an integrated, systemic or, as it is commonly called, logistical approach to managing the movement of transport, freight, information, financial, energy and other flows, served as one of the reasons for the Russian market to gain foreign goods in the export of Russian electricity, natural resources and import of transport services due to transportation of Russian cargoes by foreign ships and cars, as well as payment for services related to transportation through companies registered abroad).

If before the market reforms with a constant increase in the volume of freight traffic disproportions in the development of the main means of transport and management systems, leading to cases of unproductive downtime of the rolling stock and the non-rational use of technical means, now it is necessary to note the disproportions in the functioning of not only everything of the transport services market (TSM), but also in the functioning of the system for the delivery of foreign trade goods (SDFTG) through sea and river ports, which also leads to non-production downtime of the rolling stock, slowing moving vehicles and freight flows.

Currently, the operational management of the transportation process is broken into parts - the railway from the station to the station, the waterway from port to port, the automobile from the sender to the station and the port and from the station and port to the receiver (including direct shipments from the sender to the receiver), as discussed still in the works of Zvonkov V.V. and Komarova A.V. [1, 2, 3].

*Corresponding author: ovefimova@mail.ru 


\section{Material and methods}

Due to the accumulation of goods in excess of the established standards, marine and river vessels, thousands of wagons and cars unnecessarily stand idle on approaches to ports, which leads to the need to enter conventional prohibitions and restrictions on the shipment of cargo to these directions and often leads to disruption of the normal operation of entire polygons, and also disharmonization of the functioning of the entire transport network:

As practice shows, currently there are the following options for the mutual location of the links of the transport component in the chains of transportation of export-import and transit cargo through the territory of the former USSR when they are sent from (to) railroad stations in Russia or transshipped through Russian ports (figure 1, published in [5]). Schemes 1 and 2 take place when transporting export-import and transit cargo through Russian ports and by railways only to Russia; 3-6 - through ports to Russia, to other CIS countries, as well as to the Baltic countries; 7-9 - through the ports of the Baltic States to the CIS countries; 10-15 through the Kaliningrad port in transit through Lithuania; 16-21 - export-import and transit cargoes on the railways of Russia and other former republics of the USSR; 22-27 - from / to Russia to / from the CIS countries of the Transcaucasian region due to the closing of railroads lines in connection with military operations in Abkhazia and Chechnya. Also possible are variants of railroad transportations or by road to / from the sea or river port, as well as by vessels of the mixed "river-sea" navigation [4].

In modern conditions, the choice of the scheme for the delivery of foreign trade goods in a mixed message is influenced not only by the traditional parameters - the volume of transport, the distance and the cost of transportation, the throughput of the main lines and port capacities, but also such as the navigation time, the depth of the fairway on the approaches to the ports, payment of freight charges, the amount of customs and other charges at sea and river ports, the procedure and duration of customs and certification procedures, the interpretation by local taxation authorities regulations and instructions of the State Tax Service, convention bans, etc. Therefore, to solve this problem, an approach is needed that allows to take into account all types of elements, flows and legal relations, as well as flows of interests of transport and other markets in a single complex.

The approach based on topological ideas [24, 25], as well as digital control technologies [28, 29, 30] allow taking into account not only the cost of transportation [7, 8, 11-13], transport and cargo communication between the physical elements of trade and transport systems (TTS) - railroad. stations, ports, transshipment terminals and others, but also information and financial between the legal - the same stations and ports, subdivisions of the apparatus of JSC Russian Railways and the Ministry of Transport, forwarding and insurance companies, customs brokers, banks and others, energy flows providing transportation of transport, freight, information and financial flows, as well as the interaction of elements and flows among themselves, determined by regulatory legal documents and direct contracts, that is, the regulatory and legal framework the influence of the nature of these interactions on the functioning of SDFTG.

\section{Theory}

At present, the concept of digital technologies has become firmly established in our life and it is practically impossible to imagine life without a digital device.

Digital technologies are the representation of information in the format of zeros and ones, but now it is a constituent part of any industry. In addition, digital accounting or digital economy is a complex of information systems or computer programs. 


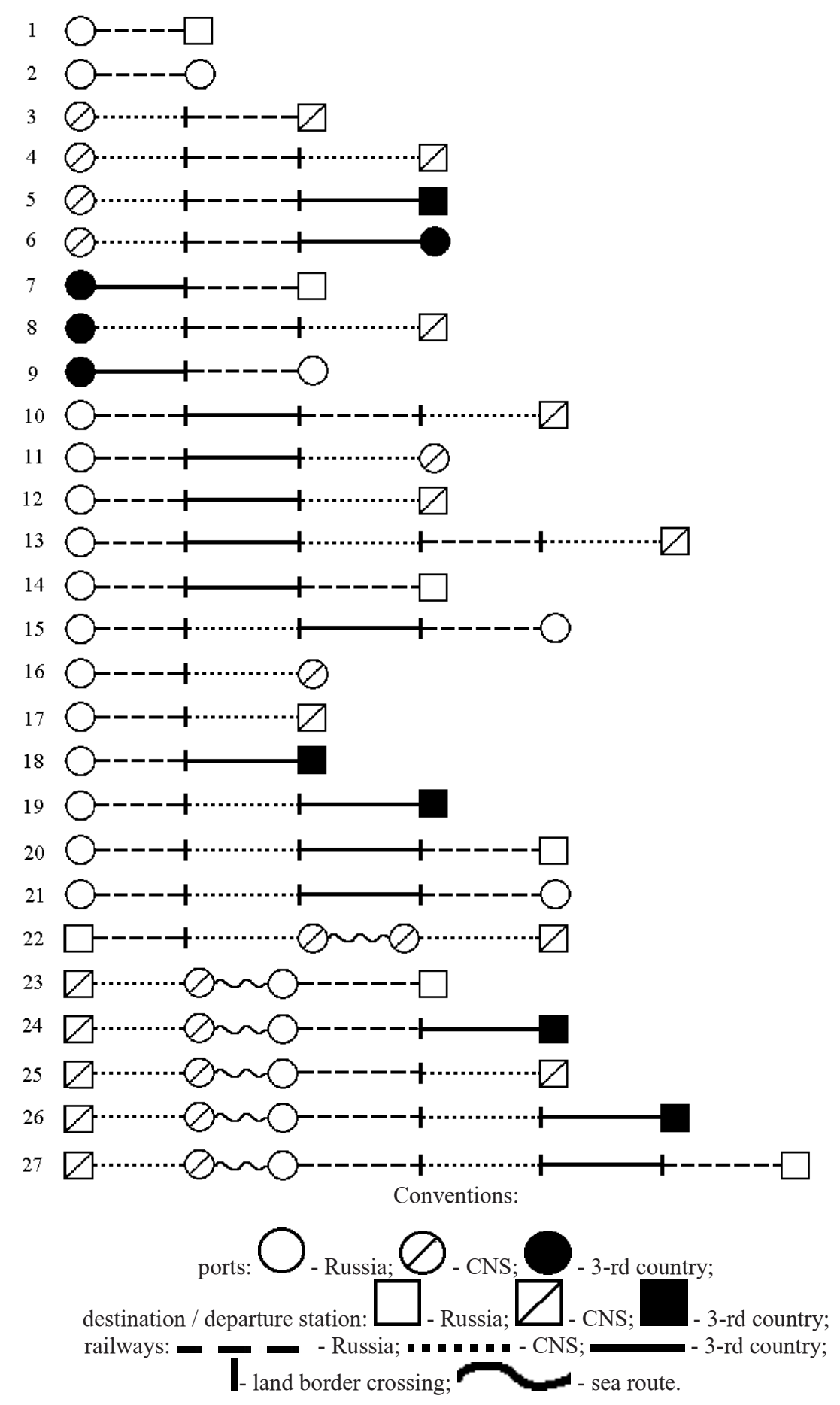

Fig. 1. Variants of schemes of delivery of foreign trade cargoes in a mixed flow involving railways

The liberalization of the commercial activities of industrial and transport enterprises, the widespread corporatization of airlines, the enterprises of motor transport, shipping companies and ports, the disintegration of the centralized settlement system for freight transportation on 
all types of transport led to the creation of a competitive environment in the transport services (ETS), in which among a variety of subjects, one of the main are freight forwarders and cargo owners [6].

As a freight forwarder, a natural or legal person who does not directly participate in the transportation process or provide additional transport services, which is, as a rule, an agent of the carrier or points of loading, unloading, border crossing, transfer to other types transport, acting on the basis of contractual relations with the latter and with customers for transport services - consignors, consignees and cargo owners. The listed entities may be both legal entities and individuals.

As cargo owners (traders) can act not only the senders or recipients of goods, but also other legal entities and individuals who are the owners of the goods transported in the considered segment of the chain of its transportation, since in the process of moving the goods to the end user there may be his repeated resale.

In the physical transfer of goods from the seller to the buyer, a complex system of relationships between the producers of goods and their consumers is formed through the delivery system, which must ensure compliance with the terms of the supply contract.

In connection with the creation of commercial structures of various forms of ownership under industrial enterprises, engaged in intermediary activities, as well as the production of bulk goods, mainly from raw materials, in shipping documents, even when loaded from the same storage capacity, as a consignor can to figure not only the manufacturer of the products or the processor of raw materials, but also the commissioner, dealer, distributor, jobber and other legal entities that are owners of the goods sent at the initial stage of the transportation process. Therefore, contracts for the provision of expert services are the last ones.

Also, freight forwarders can perform part of the functions of carriers - transportation in transport units (wagons, ships, cars or containers), performing loading and unloading operations and storing goods in warehouses leased or owned by the freight forwarder, etc. Often, one legal entity functions of cargo owners, forwarders and carriers.

In the pre-reform period, at the port of departure for foreign trade cargoes the following scheme was applied: shipper-sea merchant port-sea carrier, at the port of destination: sea carrier - sea trading port - consignee. Such schemes corresponded to the definition of the contract of sea transportation given in the Code of Merchant Shipping (1968, Ed., Article 118), since the seaport under the then acting legislation acted as agent of all shipping companies and was the forwarder of all shippers and consignees [31]. Relations between the port and sea shipping companies were regulated by internal instructions of shipping companies, and relations in the system as a whole - the contract of carriage by sea. The exit of the sea trade ports from the subordination of the shipping companies, due to the corporatization of both, and the continuing definition of the contract of carriage by sea, led to a new scheme of relations between the participants in the processes under consideration. In the port of departure of the goods: the shipper is the sea carrier; at the port of destination: sea carrier - consignee. For port operations between the carrier, the cargo owner and the producer of port services, relations now do not arise on the terms of the contract of carriage by sea, as before. These relations under the new conditions are regulated by separate contracts - transport expedition, agency, stevedoring, warehouse, survey services, etc.

Now the relations of the parties when passing through the port of export cargo, transferred from the railroad on sea transport, are defined as follows: the railway delivers the cargo to the recipient (the cargo owner or the forwarding agent representing it) on the basis of the railway contract transportation; the recipient shall deliver the cargo to the port under the terms of the contract for storage and transshipment or to the storage company under the terms of the storage agreement and the stevedoring company under the terms of the transshipment agreement; port or warehouse and stevedoring companies issue the cargo to the recipient, who then becomes the consignor, for loading onto the vessel under the terms of the contract 
for storage and transshipment; the sender surrenders the cargo to the vessel under the terms of the contract of carriage by sea. Similarly, relations are determined for imported goods [32].

\section{Results}

Taking into account the legal form, possible schemes of interaction between subjects of the SDFTG and various modes of transport for foreign trade in mixed messages are shown in Fig. 2, published in [5].

For the organization of cargo delivery in a mixed communication to the destination, the cargo owners now, in addition to contracts for the purchase of goods and for transportation, need to have an agreement with organizations that carry out storage and trans-shipment to another mode of transport, as well as providing other services, i.e. The process of registration and legal support for the reliability of transportation has become more complex and timeconsuming.

For the organization of cargo delivery in a mixed communication to the destination, the cargo owners now, in addition to contracts for the purchase of goods and for transportation, need to have an agreement with organizations that carry out storage and trans-shipment to another mode of transport, as well as providing other services, i.e. The process of registration and legal support for the reliability of transportation has become more complex and timeconsuming [33].

When choosing the direction of the flow of cargo, the port of transshipment, forwarding, stevedoring, surveyor and other companies (see Table 1, published in [5]), account is taken of the existence of relevant contracts that specify the procedure for payment for services, mutual information and other mutual obligations parties, that is, the interaction between the elements of SDFTG and the subjects of the SDFTG through the movement of transport, freight, information and financial flows, as well as the flows themselves, is determined by government documents And sectorial charters, codes, regulations, and the terms of execution of direct contracts.

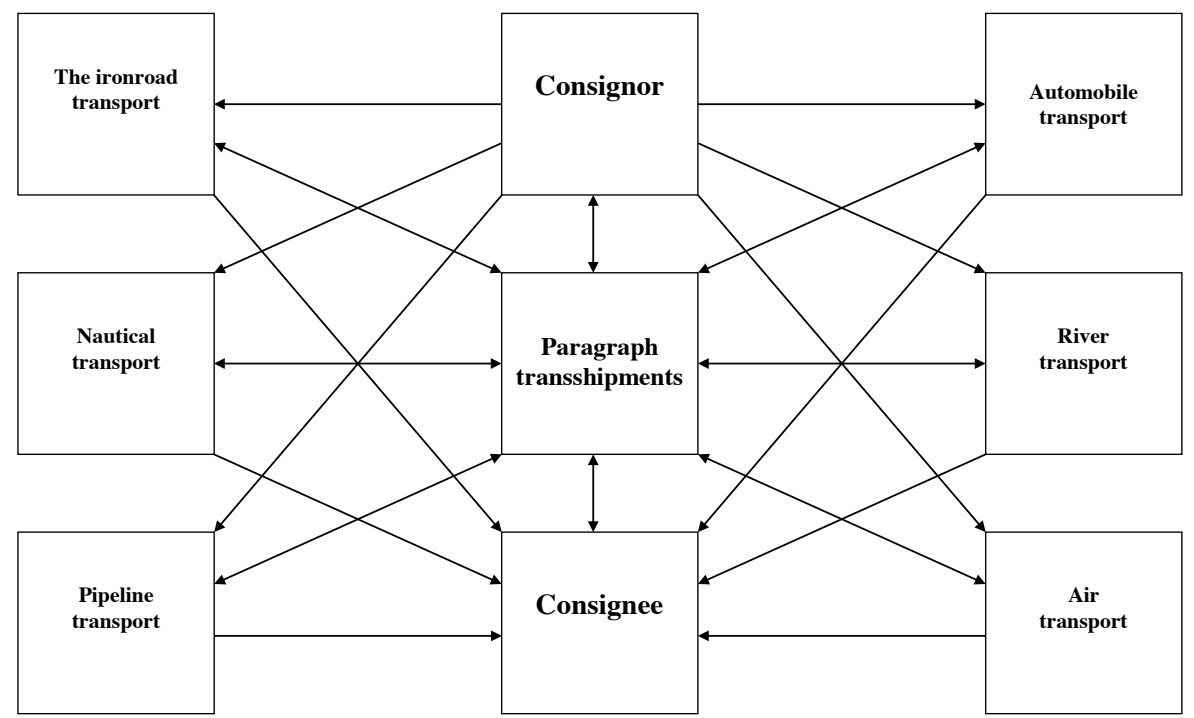

Fig. 2. Schemes of interaction of various modes of transport and subjects of the SDFTG in the system of mixed communication

From all that has been said, it follows that when choosing the route for transport (car, ship, and car-) communication and freight communication, it is necessary to take into account 
all types (interactions, interaction, coordination, representing in the aggregate the topology of the structure of SDFTG, in which various supply schemes, representing the supply chain market, are available, which, like the market of forwarding services, is an integral part of the RTU. No wonder recently there was a paraphrased saying "do not have one hundred rubles, but have ... one hundred schemes of deliveries" $[10,20]$, therefore, the problem of creating an intelligent system of selection and management of supply chains in all types of communication in the economic monitoring of one option or another and development of the transportation process [7, 8, 11-13] using modern digital information and computer technologies.

\section{Conclusion}

To achieve a synergistic effect in a single logistics space, it is necessary to form an information exchange, jointly used approaches to transportation, inventory management and storage facilities. Digital technologies allow to control the transportation process in all types of communication at a qualitatively new level, as well as all other production processes in all railways $[23,24,25]$ using all existing and prospective developments in the field of control of the transportation process at the landfills [9, 17, 18, 19, 21-22], freight and sorting stations $[14,15,16,21]$, points of interaction of various modes of transport [26], that is, in the very near future a transition to amodal transfer (see $[5,27]$ ), the control of which in all types of messages is carried out from a single dispatching center.

For groups of operations, the digital paradigm of logistics must further develop an aggregated tool for managing international supply chains.

It is also necessary to develop the concept of a marketing channel to the concept of an integrated logistics channel and the construction of supply chains, where payments and workflow must take place (both in paper and electronic form).

In the course of further development of logistics, the level of integration is constantly increasing, providing a powerful tool based on enhancing synergies.

\section{References}

1. V.V. Zvonkov, Interrelation of certain types of transport and the basis for organizing multimodal transport (as a manuscript), Academy of Railway Transport. Department of Railways. - Moscow, 139 p. (1953)

2. V.V. Zvonkov, Theoretical basis of transport operation (in the interrelation of its main types). In 10 parts. - L.: MFF / AN SSSR (1949)

3. A.V. Komarov, The interaction of rail and water transport in mixed messages, M.: River transport, 212 p. (1957)

4. S.P. Vakulenko, P.V. Kurenkov, Intermodal and multimodal transport in the transport corridors of Europe and Asia, Rail transport, 6, P.73-77 (2016)

5. P.V. Kurenkov, A.F. Kotlyarenko, Foreign trade in a mixed message, Economy. Logistics. Control. Samara: Typography "Soldier of the Fatherland", 636 p. (2003)

6. A.S. Levchenko, D.S. Belnitsky, P.V. Kurenkov, T.M. Tarasova, Logistics interaction of the coordination center of the operators of the South Ural railway and seaports, Bulletin of transport information, 11 (149), P.15-20 (2007)

7. Methods of calculation and economic indicators for the distribution of transport between modes of transport, Ed. IN AND. Dmitrieva; IKTP under the State Planning Committee of the USSR. - Moscow: Transport, 525 p. (1966) 
8. Guidelines for the development and application of specific transport costs for the location of production and distribution of transport between modes of transport, Moscow: IKTP under the USSR State Planning Committee, 232 p. (1981)

9. M.A. Nekhaev, P.V. Kurenkov, V.A. Martynchuk, Situational and logistic control system of the transportation process, Logistics and supply chain management, 5 (28), p. 25-35 (2008)

10. Majercak, J.; Kudlac, S.; Panak, M. Sustainable and Economically Efficient Five-point Supply Chain Management. Proceedings of the 20th International Scientific Conference on Transport Means, LITHUANIA Date: OCT 05-07, 2016. Book Series: Transport Means - Proceedings of the International Conference. P. 65-70 (2016)

11. Comparable costs of different modes of transport in the transport of goods, Ed. IN AND. Dmitrieva, K.N. Shimko; IKTP under the State Planning Committee of the USSR. - Moscow: Transport, 488 p. (1972)

12. Guidelines for the calculation of economic indicators for the transport of goods in different directions in railway, river and sea transport, VNIIZHT; TSNIIRF; CNIIMF. - Moscow, 32 pp. (1950)

13. T.S. Khachaturov, Methods for determining the economic efficiency of various modes of transport. Part 1. Moscow: Transzheldorizdat, 238 p. and part 2. M.:

Transzheldorizdat, Carteschemes. (1956)

14. S. Kudlac, V. Stefancova. Using the Saaty Method and the FMEA Method for Evaluation of Constraints in Logistics Chain. Conference: 10th International Scientific Conference on Transportation Science and Technology. Vilnius, Lithuania, May 04-05, 2017. Transbaltica 2017. 187. P. 749-755 (2017)

15. Kurbatova A., Kurenkov P. Selection of optimal supply schemes. XII International Scientific Conference on Agricultural Machinery Industry 10-13 September 2019. IOP Conf. Series: Earth and Environmental Science 403 (2019) https://doi:10.1088/1755$1315 / 403 / 1 / 012231$.

16. P.V. Kurenkov, M.A. Nekhaev, D.E. Stebletsov, Situational and logistics management of station processes in intelligent transport systems, Intelligent control systems for railway transport (ISUZHT-2012): Proceedings of the 1st scientific-technical. Conf., Moscow, MIIT, JSC "NIIAS", November 15-16, 2012, M.: OJSC "NIIAS", P.88-92 (2013)

17. V.P. Mokhonko, V.S. Isakov, P.V. Kurenkov, Problems of creating a situationanalytical control system for the transportation process in rail transport, Bulletin of Transport Information, 9, P.22-27 (2004)

18. V.P. Mokhonko, V.S. Isakov, P.V. Kurenkov, Support system for making economically sound decisions, Economics of railways, 1, P.18-26 (2005)

19. V.P. Mokhonko, V.S. Isakov, P.V. Kurenkov, Situational management of transportation process, Transport: science, technology, management: Sat. OI / VINITI, 11, P.14-16 (2004)

20. P.V. Kurenkov, N.Yu. Kargin, Situational management of costs of operational locomotive depots, Modern transport: infrastructure, innovations, intellectual systems: Sat. Proceedings (conference proceedings), M: International Academy of Transport, P.72-77 (2013)

21. N.N. Shabalin, Optimization of the processing of wagons at stations, Moscow: Transport, 184 p. (1973)

22. L.P. Tulupov, E.M. Zhukovsky, A.M. Gusyatiner, Automated control systems for transportation processes on railways, A manual for high schools, Moscow: Transport, 207 p. (1991)

23. S.Yu. Eliseev, A.F. Kotlyarenko, P.V. Kurenkov, To typology of logistics centers, Logistics, 3, P.15, 16, 19 (2003) 
24. Yu.A. Polyansky, P.V. Kurenkov, The road center of situational management. The problem of creation and functioning, Economics of railways, 1, P.51-66 (2003)

25. Yu.A. Polyansky, P.V. Kurenkov, Topological modeling of the interaction of railway farms, Transport: science, technology, management: Sat. OI / VINITI RAS, 7, P.8-18. (2003)

26. S.M. Rezer, P.V. Kurenkov, E.P. Shmuglakov, Model of the functioning of the transport hub based on the seaport, Bulletin of Transport, 6. pp.30-37 (the beginning); 7. - p. 41 -44 (the end). (2014)

27. A.A. Avetikyan, N.P. Solovieva, Marketing and its role in organizing the transportation process, Rail transport, 8, p. $72-77$ (1992)

28. G.V. Bubnova, P.V. Kurenkov, A.G. Nekrasov, Digital logistics and security of supply chains, Logistics, 7.7, p.46-50.

29. G.V. Bubnova, P.V. Kurenkov, A.G. Nekrasov, Integrated security of supply chains in the digital economy, Economics of railways, 7.7, P.77-66.

30. G.V. Bubnova, A.G. Nekrasov, P.V. Kurenkov, New logistics. on comprehensive security of supply chains in digitized economics, Horizons of railway transport: Zbornik prispevkov (proceeding book). Slovak Republic, University of Zilina, 21-22 September 2017, pp.26-34 (2017)

31. P.V. Kurenkov, A.V. Astafiev, Action plan (road map) for the implementation of the program for organizing piggyback transport in the space of 1520, Transport: science, technology, management: SB. Russian history, 11, P. 84 (2015)

32. P. Kurenkov, A. Astafiev, O. Kaplina, K Komunikacie, Different exegesis of the concepts related to mixed transport, 18 (2), p. 148-152 (2016)

33. P.V. Kurenkov, Yu.V. Veselov, Mechanisms of state regulation of the development of the transport system of the region, Transport: science, technology, management: SB. National history, 7, p. 8 (2006) 